\title{
Use of monoclonal antibodies in an ELISA to detect IgM class antibodies specific for Toxoplasma gondii
}

\author{
A HALFOUR, J P HARFORD, MARGARET GOODALL* \\ From the Toxoplasma Unit, The Regional Public Health Laboratory, Leeds, and the *Department of \\ Immunology, The Medical School, Birmingham
}

SUMMARY Two monoclonal antibodies $\mathrm{CH} 6$ and $\mathrm{C1E} 3$ were used in an antibody class capture assay for the detection of IgM antibodies specific for Toxoplasma gondii. CH6 was used on the solid phase to capture human IgM. After a Toxoplasma gondii antigen had been added, specifically bound material was detected using C1E3 coupled to horseradish peroxidase. The assay was compared with an established system using polyclonal antisera at both the capture and antigen detection stages. A good correlation was found, with $97.3 \%$ (125 of 128) of sera giving the same classification in both assays. Three sera were positive only in the polyclonal system. No false positive results were found when 118 negative sera were examined.

The two monoclonal antibodies provide a viable alternative to the use of polyclonal sera at the capture and antigen detection stages in the antibody class capture assay for the measurement of specific IgM against $T$ gondii.

In many infectious diseases the presence of specific antibodies of the IgM class allows a diagnosis to be made from a single serum specimen taken early in infection. Detection of specific IgM in neonatal sera is also of major value in distinguishing between a congenital infection and passively acquired maternal antibody. In the investigation of toxoplasmosis the indirect immunofluorescence test has been widely used for the detection of specific IgM. ${ }^{1}$ This assay, however, can be affected by specific IgG showing competitive inhibition and giving a false negative result, ${ }^{2}$ while rheumatoid factors and antinuclear antibodies can produce false positive results. ${ }^{3-5}$

These problems can be overcome by the antibody class capture assay (ACCA). ${ }^{6}$ Antisera bound to a solid phase is used to capture IgM from the test serum and the remaining serum components washed away. The specificity of the bound IgM can then be assayed by the addition of the antigen of interest, followed by an enzyme labelled antibody against this antigen. Standardisation of both the capture antibody and the enzyme labelled antibody of specific interest is important to ensure that the sensitivity, specificity, and reproducibility of the assay are optimised.

Although an antihuman IgM monoclonal antibody Tibi 82 has been used in a radioimmunoassay and in

Accepted for publication 9 March 1987 two reverse immunosorbent methods for specific IgM detection, it was not used in an enzyme linked immunosorbent assay (ELISA) system. ${ }^{78}$ In this study an antihuman IgM monoclonal antibody $\mathrm{CH} 6$ was used in an ACCA ELISA to detect IgM antibodies specific for Toxoplasma gondii and a second monoclonal antibody, C1E3, used at the antigen detection stage. $\mathrm{C} 1 \mathrm{E} 3$ recognises a major membrane protein antigen of $T$ gondii and will induce complement mediated cell lysis of the organism. This assay was evaluated and compared with an established ACCA ELISA in which polyclonal antisera were used.

\section{Material and methods}

Sera routinely submitted for toxoplasma serology were titrated in both the dye test and the indirect haemagglutination test (IHAT). ${ }^{9}$ A total of 128 sera with a dye test titre of $>32$ were subsequently tested in the two ACCA enzyme linked immunoabsorbent assay (ELISA) systems for specific IgM. A further 118 sera with no detectable antibody were used to test the specificity of the monoclonal assay.

ENZYME LINKED IMMUNOSORBENT ASSAY The ACCA ELISA for Toxoplasma gondii specific IgM, which uses microcuvettes for the solid phase, ${ }^{10}$ was modified to the microtitre plate format. Flat bot- 
tomed PVC microtitre plates (Falcon) were sensitised with $\mu$-chain specific antihuman IgM (Dako), diluted $1 / 1000$ in $50 \mathrm{mM}$ carbonate/bicarbonate coating buffer pH 9.6 and held at $4^{\circ} \mathrm{C}$ for two to three days.

Plates were washed by shaking out the reagent, immersing the plate in $10 \mathrm{mM}$ phosphate buffered saline, pH 7.2 (PBS), containing $0.05 \%$ Tween 20 (PBST), and again shaking out a total of nine times, followed by draining.

Sera were diluted to $1 / 200$ in PBST containing $2 \%$ blocking agent and $100 \mu \mathrm{l}$ delivered into duplicate test wells, followed by incubation for four hours at room temperature. The blocking agent was prepared from normal human serum, negative in the dye test. After the immunoglobulin fraction had been removed by precipitation with $35 \%$ saturated ammonium sulphate, the supernatant was dialysed against tap water and PBS and stored at $-20^{\circ} \mathrm{C}$.

Four serum controls were run on each plate, a negative, a low, and a high IgM positive, as well as a reference standard, produced "in-house" and ascribed an arbitrary value of 100 enzyme immunoassay units (EIU). A conjugate control well with diluent instead of serum, or antigen and a substrate control well, with diluent at the serum, antigen, and conjugate stages, were also included.

After the serum incubation the plates were washed and $100 \mu$ l of antigen diluted $1 / 500$ in PBST containing $5 \%$ of the blocking agent was added to all wells except the conjugate and substrate controls. The plates were incubated at $4^{\circ} \mathrm{C}$ overnight.

Antigen was prepared from parasites of the RH strain, harvested from cotton rats (Sigmodon hispidis). Parasites were suspended in distilled water in the ratio of $10 \mu \mathrm{l}: 10^{8}$ organisms followed by three cycles of freezing in liquid nitrogen and thawing at $37^{\circ} \mathrm{C}$ to induce lysis. ${ }^{11}$ After centrifugation $(2000 \mathrm{~g}$ for 10 minutes) the supernatant was retained as the antigen and stored at $-20^{\circ} \mathrm{C}$.

For the detection of bound antigen, serum from a well defined case of glandular toxoplasmosis ${ }^{12}$ was fractionated, the IgG isolated and the $F\left(a b^{\prime}\right)_{2}$ fragment conjugated with horseradish peroxidase ${ }^{13}$ This was diluted to $1 / 50000$ in PBST containing $5 \%$ of the blocking agent for use. After washing the plates $100 \mu \mathrm{l}$ was added to all wells except the conjugate control, followed by incubation for two hours at room temperature, then further washing.

TMB $\left(3,3^{\prime}, 5,5^{\prime}\right.$-tetramethylbenzidine $)$ substrate $(100 \mu \mathrm{l})$ was added to all wells on the plate. The TMB $(0.42 \mathrm{mM})$ was dissolved in dimethylsulphoxide, then diluted in $100 \mathrm{mM}$ sodium acetate/citric acid buffer pH 6.0, with $1.3 \mathrm{mM}$ hydrogen peroxide added just before use. TMB is non-carcinogenic and shows a greater sensitivity than the more commonly used horseradish peroxidase substrates. ${ }^{14}$ After one hour
Balfour, Harford, Goodall

at room temperature the reaction was stopped by the addition of $50 \mu \mathrm{l}$ of $2 \mathrm{M}$ sulphuric acid.

An automatic plate reader (Artek Systems, supplied by New Brunswick Scientific UK Ltd, Watford) coupled to an Apple II + microcomputer was used to read the absorbance values at $450 \mathrm{~nm}$ after blanking on the substrate control well. An evaluation program was developed to average duplicates and calculate the IgM concentration in EIUs as a percentage of the in-house reference serum, using the equation:

EIUs $=\frac{\text { Test Absorbance-negative control absorbance }}{\text { Reference Absorbance-negative control absorbance }} \times 100$ where Abs is the absorbance at $450 \mathrm{~nm}$.

Subtracting the negative control serum value has the effect of setting this to 0 EIUs. A printout was produced identifying the run and showing the mean absorbance values for both the positive and the nega- of tive control sera, as well as the positive:negative ratio 은 for these two sera. In addition, the sample identification, mean absorbance reading, and IgM value were shown for each set of duplicate wells. Sam- 을 ples showing absorbance values differing by more $\stackrel{5}{\circ}$ than $10 \%$ were automatically flagged and normally $\vec{\circ}$ rejected. A run was only accepted if the ratio of the $\infty$ positive:negative control sera was $>2 \cdot 5$, the various control wells gave readings within defined limits, and the coefficient of variation of the standard serum, loaded in sequence at both the beginning and end of the plate, was less than $10 \%$. High and low positive controls were expected to fall within $+/-2$ standard deviations of their previously established mean value and their performance on each plate was monitored on a Shewhart chart. ${ }^{15}$

The assay was used on more than 2000 specimens over a period of two years and has proved a valuable aid in the immunodiagnosis of this disease (data not presented).

MONOCLONAL ANTIBODY TO HUMAN IgM Hybridoma line CH6 (available from The Binding Site, Birmingham B15 2SQ) was produced by the fusion of NS1 cells with spleen cells from immunised BALB/c mice, using established techniques. ${ }^{16}$ It was selected for its antihuman IgM activity in an indirect $\widetilde{N}$ haemagglutination assay and an inhibition assay $N$ using sensitised sheep red cells. ${ }^{17}$ This monoclonal N antibody is of the $\operatorname{IgG}_{1}$ isotype and specific for IgM $\sigma$ with either $\kappa$ or $\lambda$ light chains, giving negative titres with $\gamma, \delta$ or $\alpha$ heavy chains and free $\kappa$ or $\lambda$ light chains.

MONOCLONAL ANTIBODY TO Tgondii

A monoclonal antibody $\mathrm{ClE} 3$, which reacts with a $\frac{T}{0}$ major $35 \mathrm{Kd}$ membrane component of $T$ gondii, ${ }^{18} \stackrel{\overrightarrow{\mathbb{D}}}{\mathrm{d}}$ was used for antigen detection. The hybridoma grows $\frac{\rho}{\mathbb{D}}$ well in mice, readily producing ascitic fluid with a dye 
test titre of $>1 / 128000$. The IgG fraction was isolated by affinity chromatography and conjugated with horseradish peroxidase. ${ }^{13}$

\section{ELISA BINDING OF MONOCLONAL}

ANTIHUMAN IgM

The standard polyclonal ELISA system was modified to evaluate the binding of the murine monoclonal antihuman IgM antibody. Dilutions of ascitic fluid were prepared in coating buffer, over the range $1 / 100$ to 1/5000 and used for the sensitisation of six wells at each dilution. A set of control wells was sensitised with the polyclonal antiserum. The positive and negative control sera were run in duplicate, together with a conjugate and substrate control, at each level of sensitisation.

Absorbance readings were evaluated for good discrimination between the positive serum $(>0.5)$ and negative serum $(<0 \cdot 1)$, with low background levels in the conjugate control $(0 \cdot 08)$. CH6 showed evidence of binding, with an optimal titre of $1 / 2500$ that was used in subsequent studies.

TITRATION OF THE MONOCLONAL ANTI-T gondii-HRP CONJUGATE

The capture antibody $\mathrm{CH} 6$ was used at the optimum titre of $1 / 2500$ for plate sensitisation. The C1E3-HRP conjugate was then titrated over the range $1 / 100$ to $1 / 5000$, using the positive and negative control sera with a conjugate and control well as described for the anti-IgM screen. An optimum titre was found to be $1 / 400$, and this was used in subsequent studies.

\section{Results}

\section{COMPARISON OF THE MONOCLONAL AND}

POLYCLONAL ELISA

A total of 128 sera containing antibodies to $T$ gondii were tested for specific IgM by both ELISA systems and the results compared. Good agreement between the monoclonal (mELISA) and polyclonal (pELISA) systems was found, with a correlation coefficient $(r)$ of 0.93 (fig).

Reference to the clinical history, symptoms, and results of other serological tests has enabled us to

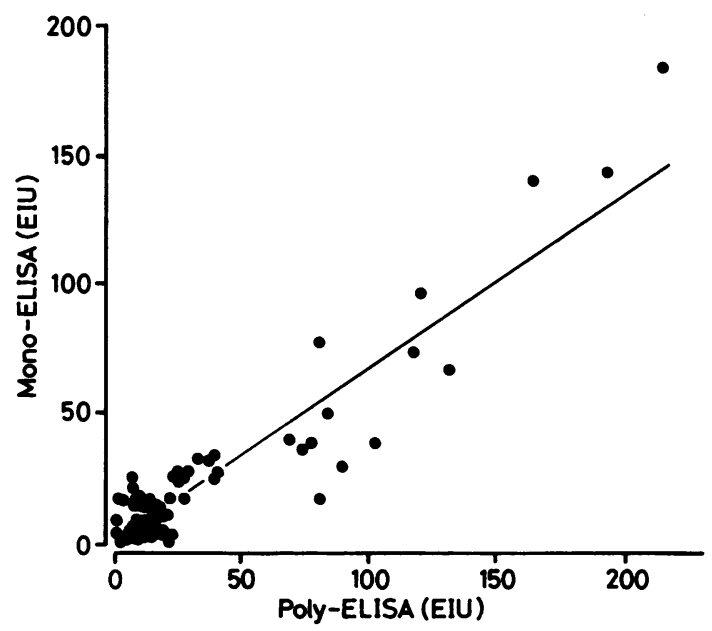

Figure Correlation of monoclonal and polyclonal ELISA systems for detecting Toxoplasma gondii specific human IgM, using antibody class capture technique. $(Y=0.09+0.68 X)$

define various levels of significance in the pELISA. Values $=>35$ EIUs were regarded as positive for specific IgM, those $=<25$ EIUs as negative, with the range of 26-34 EIUs classed as doubtful positive, although further experience in the application of these levels is needed. When this classification was applied, with an allowance of up to 5 EIUs, $97.7 \%$ (125 of 128) of the sera gave the same result in both assays. The remaining three sera were all positive in the pELISA but gave a negative or doubtful positive result in the mELISA. The serological profile and clinical information for these patients suggested relatively recent $T$ gondii infections (table).

\section{SPECIFICITY OF THE MELISA}

The specificity of the mELISA was tested by evaluating 118 sera from patients having symptoms compatible with toxoplasmosis but showing no serological evidence of infection when tested by dye test, IHAT, and pELISA. All were negative in the monoclonal system, $116(98 \%)$ had values of $<=10$ EIUs, the remaining sera having values of 15 and 19 EIUs.

Table Sera showing discrepant results between the polyclonal (pELISA) and the monoclonal (mELISA) enzyme immunoassays (ELISA results are expressed in arbitrary units of EIU)

\begin{tabular}{llllllll}
\hline Serum & Dye test titre & IHAT titre & pELISA & mELISA & Age & Sex & Notes \\
\hline 1 & 8192 & 128 & 43 & 27 & 26 & F & Lymphadenopathy, suggestive \\
histology \\
2 & 256 & 256 & 40 & 24 & 31 & F & $\begin{array}{c}\text { Miscarriage, rising dye test titre } \\
\text { Lymphadenopathy 5 months, } \\
\text { suggestive histology }\end{array}$ \\
\hline
\end{tabular}




\section{Discussion}

This study has shown the practical application of two monoclonal antibodies in an ELISA using the class capture technique and that the system gives results similar to those obtained with an established assay that uses polyvalent antisera. The identification of a monoclonal anti-IgM, which binds to the solid phase at a high dilution, will provide better standardisation of immunoassays for specific IgM class antibody. This should encourage the development of antibody class capture assays for use in other infectious diseases where IgM detection is of particular value in immunodiagnosis. ${ }^{19}$

The anti- $T$ gondii monoclonal antibody C1E3 was selected specifically for its ability to induce complement mediated cell lysis of the living parasite in the methylene blue dye test, regarded as the definitive test system for the detection of antibodies against this organism. This antibody is of the $\mathrm{IgG}_{3}$ subclass. It recognises a major cell membrane antigen on the surface of the parasite and provides a high level of protection against infection (unpublished data). It has been shown that in the course of infection IgM class antibodies against the antigen recognised by C1E3 give a maximal response by two months, although clinically important antibody titres were detected for up to six months. ${ }^{20}$ The response between individuals, however, can show a lot of variation. In the study of a laboratory acquired infection IgM had started to fall by five weeks and became negative by four months.

The three sera that gave discrepant results were classified as positive in the pELISA but negative by the mELISA. Further experience with the mELISA may show the need to change the cut off value between positive and negative. If a value of 25 EIUs had been used sera 1 and 2 (table) would be regarded as positive. The third serum, from a patient with a five month history of swollen glands, would still be classed as negative. If IgM titres measured by the mELISA are shown to have a more transient response than occurs with the pELISA, this would be of value in distinguishing acute and long term infections.

Both the mELISA and pELISA systems gave very similar results, indicating that the membrane antigen against which the C1E3 anti- $T$ gondii is directed is a major antigenic component of the organism, against which IgM class antibodies are produced in the course of a natural infection. Identification of this antigen may be important in the development of a vaccine. It may also be suitable for use in a system for passive immunisation where there is a risk of toxoplasmosis, particularly in seronegative recipients receiving a heart from a seropositive donor, ${ }^{21}$ or in providing fetal protection when seroconversion has occurred during pregnancy.

The monoclonal antibody $\mathbf{P} 30$, also directed against a major cell membrane protein of $T$ gondii, ${ }^{22} \stackrel{\overrightarrow{\vec{F}}}{ }$ has been used in a similar ACCA for the detection of $\stackrel{9}{+}$ specific IgM, but polyclonal antihuman IgM serum was used for the antigen capture stage. ${ }^{23}$ This assay $\frac{\bar{\sigma}}{\overline{0}}$ has given good results in the immunodiagnosis of $\frac{\bar{D}}{\vec{D}}$ recent $T$ gondii infections and detected IgM in sera $\varrho$ with clinically acute infections negative for IgM by an indirect immunofluorescence test.

The use of both these monoclonal antibodies $\mathrm{CH} 6$ and $\mathrm{C} 1 \mathrm{E} 3$ at high dilutions in the antibody class cap- $\vec{\omega}$ ture assay should reduce the incidence of non-specific $\mathrm{O}$ reactions due to the presence of antinuclear anti- 용 bodies, rheumatoid factor, or any other inhibitory ${ }^{\circ}$ factors. Lower background absorbances and $\infty$ increased sensitivity can be expected in addition to the of increased specificity. With low background values the $\mathcal{E}$ expression of results as a signal:noise ratio is no 을 longer necessary. The expression of results as a per- $\rightarrow$ centage value of a predefined control serum is more useful and provides a practical way of comparing assays directly, irrespective of the absolute absorb- $\stackrel{\oplus}{\rightarrow}$ ance values. The use of a numerical scale to express $\vec{\varphi}$

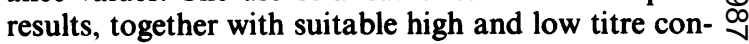
trol sera allows an appraisal of the interassay and intra-assay performance to be made. This is useful for quality control and validation of assay runs (unpublished data). We have set up a United Kingdom standard for use in the ACCA system, but there $\frac{\square}{\square}$ is need for an international standard serum with $\varrho$ which assays for the detection of specific IgM against $\overrightarrow{\overrightarrow{0}}$ $T$ gondii can be calibrated.

We are indebted to Mr R Payne and Mr M Isaac at the Public Health Laboratory, Swansea, for carrying out the C1E3-HRP conjugation.

\section{References}

1 Remington JS, Desmonts G. Congenital toxoplasmosis: vari- 3 ability in the IgM fluorescent diagnosis. $J$ Pediatr 1973;83: 음 23-30.

2 Carosi G, Filice G, Meroni V, Beloni C, Gerola O, Pesando P. D Congenital toxoplasmosis: screening of 963 mothers and their children at birth. International Journal of Biological Research in Pregnancy 1981;2:117-22.

3 Naot Y, Remington JS. An enzyme-linked immunosorbent assay for detection of IgM antibodies to Toxoplasma gondii: use for diagnosis of acute acquired toxoplasmosis. $J$ Infect Dis 1980;142:757-66.

4 Naot Y, Barnett EV, Remington JS. Method for avoiding falsepositive results occurring in IgM enzyme-linked immunosorbent assays due to the presence of both rheumatoid factor $\bar{D}$ and antinuclear antibodies. $J$ Clin Microbiol 1981;14:73-8.

5 Naot Y, Desmonts G, Remington JS. IgM enzyme-linked $\square$ immunosorbent assay test for the diagnosis of congenital toxoplasma infection. J Pediatr 1981;98:32-6.

6 Duermeyer W, van der Veen J. Specific detection of IgMantibodies by ELISA, applied in hepatitis A. Lancet $\overrightarrow{\mathbb{D}}$ 1978;ii:684. 
7 Pouletty P, Pinon JM, Garcia-Gonzalez M, Desmonts G, Thulliez $P$, Thoannes $H$, Kadouche J. An anti-human immunoglobulin $\mathbf{M}$ monoclonal antibody for detection of antibodies to Toxoplasma gondii. Eur J Clin Microbiol 1984;3:510-5.

8 Pouletty P, Kadouche J, Garcia-Gonzalez M, et al. An antihuman $\mu$ chain monoclonal antibody: Use for detection of IgM antibodies to Toxoplasma gondii by reverse immunosorbent assay. J Immunol Methods 1985;76:289-98.

9 Balfour AH, Fleck DG, Hughes HPA, Sharp D. Comparative study of three tests (dye test, indirect haemagglutination test, latex agglutination test) for the detection of antibodies to Toxoplasma gondii in human sera. J Clin Pathol 1982;33:228-32.

10 Payne RA, Isaac M, Francis JM. Enzyme-linked immunosorbent assay (ELISA) using class capture for the detection of antitoxoplasma IgM. J Clin Pathol 1982;35:892-6.

11 Francis JM. A contribution towards the antigenic analysis of Toxoplasma gondii. Med Lab Sci 1983;40:319-25.

12 Hughes HPA, Balfour AH. An investigation of the antigenic structure of Toxoplasma gondii. Parasite Immunol 1981;3: 235-48.

13 Isaac M, Payne RA. Antibody class capture assay (ACCA) for rubella-specific IgM antibody. J Med Virol 1982;10:55-64.

14 Bos ES. 3,3',5,5'-tetramethylbenzidine as an Ames test negative chromogen for horse-radish peroxidase in enzyme-immunoassay. J Immunoassay 1981;2:187-204.

15 Westgard JO, Barry MR. A multi-rule Shewhart chart for quality control in clinical chemistry. Clin Chem 1981;27:493-501.

16 Galfre G, How SC, Milstein C, Butcher GW, Howard JC. Anti- bodies to major histocompatibility antigens produced by hybrid cell lines. Nature (Lond) 1977;266:550-2.

17 Lowe J, Hardie D, Jefferis R, et al. Properties of monoclonal antibodies to human immunoglobulin kappa and lambda chains. Immunology 1981;42:649-59.

18 Wright JP, Balfour AH. Monoclonal antibodies to Toxoplasma gondii. Proceedings in Parasitology. London: British Society of Parasitology, 1983:16.

19 Forghani B, Myoraku CK, Schmidt NJ. Production of monoclonal antibodies to human IgM for assay of viral IgM antibodies. $J$ Virol Methods 1982;5:317-27.

20 Payne RA, Joynson DHM, Balfour AH, et al. Public Health Laboratory Service enzyme linked immunosorbent assay for the detection of toxoplasma specific IgM antibody. J Clin Pathol 1987;40:276-81.

21 McGregor CGA, Fleck DG, Nagington J, Stovin PGI, Cory-Pearce R, English TAH. Disseminated toxoplasmosis in cardiac transplantation. J Clin Pathol 1984;37:74-7.

22 Rodriguez C, Afchain D, Capron A, Dissous C, Santoro F. Major surface protein of Toxoplasma gondii contains an immunodominant region with repetitive epitopes. Eur $J$ Immunol 1985;15:747-9.

23 Cesbron JY, Capron A, Ovlaque G, Santoro F. Use of a monoclonal antibody in a double-sandwich ELISA for detection of IgM antibodies to Toxoplasma gondii major surface protein (P30). J Immunol Methods 1985;83:151-8.

Requests for reprints to: Dr AH Balfour, Toxoplasma Unit, The Regional Public Health Laboratory, Bridle Path, York Road, Leeds LS15 7TR, England. 